\title{
Assessment of the quality of life of cardiac patients after coronary artery bypass grafting
}

\begin{abstract}
Results of quality of life in 158 patients who underwent cardiac surgery due to the acute coronary syndrome are presented. Quality of life was assessed by using the SF-36 questionnaire. Groups were formed by age and by gender. It was revealed there are more patients with average and increased the quality of life in a group with surgical revascularization. Results were statistically insignificant in the age group up to 65 years and over 65 years of age, except the $\mathrm{MH}(\mathrm{p}=0,02)$. Statistically significant difference was registered in $\mathrm{RE}$ indicator $(\mathrm{p}=0,02)$ when comparing men and women physical and mental health. A statistically significant difference $(\mathrm{p}<0,001)$ in all indicators was registered in both age groups during 1 and 6 months, 1 and 12 months. There is no statistically significant difference between people with secondary and higher education.
\end{abstract}

Keywords: coronary bypass surgery, acute coronary syndrome, quality of life, SF36 questionnaire

Volume 3 Issue 6 - 2018

\author{
MA Kamaliyev,' AB Almukhanova ${ }^{2}$ \\ 'Department of public health and health service, National \\ Medical University, Kazakhstan \\ ${ }^{2}$ Department of internal diseases №2, National Medical \\ University, Kazakhstan
}

\begin{abstract}
Correspondence: Aizhan Almukhanova, Department of internal diseases №2, National Medical University, Tole bi street, 94, Almaty, Republic of Kazakhstan, Tel +77019710555,
\end{abstract} Email almavzhan@mail.ru

Received:September 10, 2018 | Published: December 14, 2018

\section{Relevance of article}

According to the official statistics viewed in a longer time-frame in the Republic of Kazakhstan there is a prevalence rate of circulatory system diseases increased in 2,1 times: from 1153,9 per 100.000 population in 1991 to 2429,7 per 100.000 population in 2015 ; including adults (from the age of 18 and over) in 2,2 times (from 1511,4 per 100.000 population in 1991 up to 3326,8 per 100.000 population in 2015). ${ }^{1}$ Active development of a technologically advanced medical treatment for patients with an acute coronary syndrome in the Republic of Kazakhstan started in 2007.

In Kazakhstan cardiological, an interventional cardiology and cardiosurgical treatments are provided by: 1) cardiac center and/or dispensary; 2)cardiosurgical center; 3)medical organizations that have organized departments of cardiology, interventional cardiology and cardiosurgical department, rehabilitation department, cardiological room. There were 4068 coronary bypass surgeries made in 2013-2015 in the Republic of Kazakhstan, most of them are made in Almaty $(23,3 \%)$ and Astana $(16,8 \%)$ and minority in Pavlodar district $(1,2 \%)$ and Kostanay district $(0,4 \%)$.

Index of coronary bypass due to an acute coronary syndrome in people over 50 years of age was 23, 6 in 2013; 32, 9 in 2014 and 44, 5 per 100.000 population in 2015 and it fluctuated significantly in due to territory districts. ${ }^{2}$ In this regard, a significant scientific and practical interest that presents a study of the quality of life $(\mathrm{KZH})$ as a criterion of quality of medical care considered as an active and reliable indicator used in a comprehensive assessment of the quality of medical care. ${ }^{3}$ It should be noted that there is little literature available that addresses the effectiveness of coronary bypass in research of the quality of life in patients who underwent surgical procedures of the heart and main vessels. In this regard, the study of effective treatment and improvement of the KZH shown to be relevant.

\section{Materials and methods}

The quality of life was studied in 158 patients with an acute coronary syndrome (ACS) who received treatment status post coronary artery bypass grafting $(\mathrm{CABG})$ in the Almaty City Cardiac Center, (Almaty,
Kazakhstan) in 2015. 157 patients were reinterviewed in a 6 month and 131 patients were reinterviewed 12 months after their surgery.

To investigate the quality of life, we used a Russified version of the international certified questionnaire Medical Outcomes Study Form (SF-36). The SF-36 questionnaire consists of 11 questions and 36 subquestions, all of them are grouped in eight scales: Physical Functioning (PF), Role-Physical Functioning (RP), Bodily Pain (BP), General Health (GH), Vitality (VT), Social Functioning (SF), RoleEmotional State (RE) and Mental Health (MH).

The value of each indicator on each scale varies between 0 and 100: the higher the indicator, the better the quality of life. Scales are grouped into two indicators: physical health component $(\mathrm{PH})$ and psychological component of health (MH).

The interpretation of the test results was carried out as a percentage: $0-20 \%$ - low quality of life; $21-40 \%$ - low; $41-60 \%$ - average; $61-$ $80 \%$ - increased level of quality of life and $81-100 \%$ - high quality of life. Statistical processing of results was carried out using the program "SPSS" version 20.0 (online version). The averages and standard deviations were defined. The Mann-Whitney and Kruskal Wallace criteria were used to assess the reliability of the obtained values.

These indicators were compared in two age groups (up to 65 years and after 65 years), the differences was statistically insignificant for all indicators, except $\mathrm{MH}(\mathrm{p}=0.02)$ (Table 1).

In comparing physical and mental health indicators between men and women, statistically significant differences were observed in indicator RE ( $\mathrm{p}=0.02)$ (Table 2).

There is no statistically significant difference in the rates among those who had secondary and higher education (Table 3 ).

In the age groups up to 65 and over 65 years old the difference in performances is statistically significant for all the indicators, between 1 and 6 months, 1 and 12 months $(\mathrm{p}<0.001)$ (Table 4).

In conclusion the statistical estimates distribution, quality of life can be characterized following way: Physical Functioning (PF) in patients with ACS after CABG increased from $57,48 \pm 27,46$ points to 
$62,56 \pm 26,31$ points throughout the year, i.e. this figure is interpreted as "elevated", which means it is narrowly reflected on patients' restriction of physical activity (self-care, climbing stairs, lifting heavy things and etc.) Role-Physical Functioning (RP) in patients after CABG is remained stable: from $55,22 \pm 34,21$ points to $56,68 \pm 27,17$ and can be characterized as "average". Role-Emotional State (RE) in patients after CABG increased from $49,05 \pm 39,08$ points up to $66,22 \pm 27,19$ points. This result is assessed as "elevated" and this ratio is indicative of the patients' emotional state largely doesn't bother in their day-to-day life.

Table I Data of physical and mental health of patients with the ACS after CABG in various age groups

\begin{tabular}{|c|c|c|c|c|}
\hline Indicators & $\begin{array}{l}\text { Total, } \\
\text { mean } \pm S D\end{array}$ & $\begin{array}{l}\text { Under 65, } \\
\text { mean } \pm S D\end{array}$ & $\begin{array}{l}\text { After } 65, \\
\text { mean } \pm S D\end{array}$ & P (age difference within the group) \\
\hline \multicolumn{5}{|l|}{$\mathrm{GH}$} \\
\hline 1 month & $56,70 \pm 16,23$ & $57,06 \pm 15,79$ & $55,96 \pm 17,23$ & $p=0,25$ \\
\hline 6 month & $65,21 \pm 16,65$ & $67,19 \pm 16,86$ & $61,52 \pm 15,69$ & \\
\hline 12 month & $69,15 \pm 17,63$ & $70,74 \pm 17,45$ & $66,30 \pm 17,77$ & \\
\hline \multicolumn{5}{|l|}{$\mathrm{PH}$} \\
\hline 1 month & $57,48 \pm 27,46$ & $57,81 \pm 26,26$ & $56,81 \pm 30,01$ & $p=0,06$ \\
\hline 6 month & $57,94 \pm 25,17$ & $60,09 \pm 24,98$ & $53,60 \pm 25,22$ & \\
\hline 12 month & $62,56 \pm 26,31$ & $64,88 \pm 25,73$ & $58,43 \pm 27,12$ & \\
\hline \multicolumn{5}{|l|}{$\mathrm{RP}$} \\
\hline 1 month & $55,22 \pm 34,21$ & $57,08 \pm 33,76$ & $51,44 \pm 35,15$ & $p=0,87$ \\
\hline 6 month & $53,03 \pm 27,92$ & $56,67 \pm 2926$ & $45,67 \pm 23,59$ & \\
\hline 12 month & $56,68 \pm 27,17$ & $57,44 \pm 27,92$ & $55,32 \pm 26,03$ & \\
\hline \multicolumn{5}{|l|}{ BP } \\
\hline 1 month & $55,09 \pm 23,79$ & $53,81 \pm 24,61$ & $57,69 \pm 22,02$ & $p=0,13$ \\
\hline 6 month & $55,20 \pm 22,65$ & $55,27 \pm 25,25$ & $55,06 \pm 21,58$ & \\
\hline 12 month & $64,67 \pm 27,06$ & $66,34 \pm 27,87$ & $61,74 \pm 25,58$ & \\
\hline \multicolumn{5}{|l|}{$\mathrm{MH}$} \\
\hline 1 month & $58,23 \pm 17,07$ & $57,05 \pm 17,61$ & $60,65 \pm 15,80$ & $p=0,02$ \\
\hline 6 month & $68,23 \pm 15,45$ & $69,57 \pm 15,30$ & $65.52 \pm 15,53$ & \\
\hline 12 month & $71,04 \pm 15,87$ & $72,21 \pm 15,37$ & $68,94 \pm 16,70$ & \\
\hline \multicolumn{5}{|l|}{ RE } \\
\hline 1 month & $49,05 \pm 39,08$ & $48,82 \pm 38,48$ & $49,52 \pm 40,67$ & $p=0,59$ \\
\hline 6 month & $60,99 \pm 34,24$ & $63,33 \pm 34,33$ & $56,25 \pm 33,89$ & \\
\hline 12 month & $66,22 \pm 27,19$ & $65,48 \pm 26,86$ & $67,55 \pm 28,03$ & \\
\hline \multicolumn{5}{|l|}{ SF } \\
\hline 1 month & $59,90 \pm 22,60$ & $57,80 \pm 21,44$ & $64,17 \pm 24,45$ & $p=0,62$ \\
\hline 6 month & $47,48 \pm 22,48$ & $46,43 \pm 19,01$ & $49,62 \pm 29,18$ & \\
\hline 12 month & $70,38 \pm 20,33$ & $69,13 \pm 20,50$ & $72,62 \pm 20,04$ & \\
\hline \multicolumn{5}{|l|}{ V } \\
\hline 1 month & $54,07 \pm 18,72$ & $53,30 \pm 18,90$ & $55,63 \pm 18,42$ & $p=0,26$ \\
\hline 6 month & $55,97 \pm 17,51$ & $56,10 \pm 17,26$ & $55,73 \pm 18,16$ & \\
\hline 12 month & $60,10 \pm 16,52$ & $60,06 \pm 16,20$ & $60,17 \pm 17,25$ & \\
\hline
\end{tabular}


Table 2 Physical and mental health data of patients with ACS after CABG based on sex

\begin{tabular}{|c|c|c|c|c|}
\hline Indicators & $\begin{array}{l}\text { Total } \\
\text { mean } \pm S D\end{array}$ & $\begin{array}{l}\text { Men } \\
\text { mean } \pm S D\end{array}$ & $\begin{array}{l}\text { Women } \\
\text { mean } \pm S D\end{array}$ & $P$ (sex difference within the group) \\
\hline \multicolumn{5}{|l|}{$\mathrm{GH}$} \\
\hline 1 month & $56,70 \pm 16,23$ & $57,63 \pm 16,58$ & $54,02 \pm 15,04$ & \multirow[t]{3}{*}{$p=0,70$} \\
\hline 6 month & $65,31 \pm 16,65$ & $66,18 \pm 16,96$ & $62,85 \pm 15,67$ & \\
\hline 12 month & $69,15 \pm 17,63$ & $70,29 \pm 17,74$ & $66,11 \pm 17,20$ & \\
\hline \multicolumn{5}{|l|}{$\mathrm{PH}$} \\
\hline 1 month & $57,48 \pm 27,46$ & $57,381 \pm 28,17$ & $57,78 \pm 25,64$ & \multirow[t]{3}{*}{$p=0,49$} \\
\hline 6 month & $57,94 \pm 25,17$ & $58,92 \pm 26,05$ & $55,15 \pm 22,56$ & \\
\hline 12 month & $62,56 \pm 26,31$ & $63,83 \pm 27,15$ & $59,22 \pm 24,01$ & \\
\hline \multicolumn{5}{|l|}{ RP } \\
\hline 1 month & $55,22 \pm 34,21$ & $57,69 \pm 34,34$ & $48,17 \pm 33,25$ & \multirow[t]{3}{*}{$p=0,65$} \\
\hline 6 month & $53,03 \pm 27,92$ & $55,82 \pm 28,43$ & $45,12 \pm 25,13$ & \\
\hline 12 month & $56,68 \pm 27,17$ & $57,37 \pm 27,74$ & $54,86 \pm 25,92$ & \\
\hline \multicolumn{5}{|l|}{ BP } \\
\hline 1 month & $55,09 \pm 23,79$ & $54,59 \pm 23,24$ & $56,51 \pm 25,54$ & \multirow[t]{3}{*}{$p=0,45$} \\
\hline 6 month & $55,20 \pm 22,65$ & $55,85 \pm 24,06$ & $53,34 \pm 24,14$ & \\
\hline 12 month & $64,67 \pm 27,06$ & $65,80 \pm 27,36$ & $61,69 \pm 26,40$ & \\
\hline \multicolumn{5}{|l|}{$\mathrm{MH}$} \\
\hline 1 month & $58,23 \pm 17,07$ & $58,13 \pm 17,27$ & $58,54 \pm 16,69$ & \multirow[t]{3}{*}{$p=0,44$} \\
\hline 6 month & $68,23 \pm 15,45$ & $68,35 \pm 14,52$ & $67,88 \pm 18,01$ & \\
\hline 12 month & $71,04 \pm 15,87$ & $71,83 \pm 14,79$ & $68,94 \pm 18,50$ & \\
\hline \multicolumn{5}{|l|}{ RE } \\
\hline 1 month & $49,05 \pm 39,08$ & $48,08 \pm 39,68$ & $51,83 \pm 37,66$ & \multirow[t]{3}{*}{$p=0,02$} \\
\hline 6 month & $60,99 \pm 34,24$ & $63,58 \pm 34,16$ & $53,66 \pm 24,14$ & \\
\hline 12 month & $66,22 \pm 27,19$ & $67,37 \pm 26,06$ & $63,19 \pm 30,17$ & \\
\hline \multicolumn{5}{|l|}{ SF } \\
\hline 1 month & $59,90 \pm 22,60$ & $58,85 \pm 23,74$ & $62,90 \pm 18,89$ & \multirow[t]{3}{*}{$p=0,48$} \\
\hline 6 month & $47,48 \pm 22,48$ & $47,28 \pm 22,11$ & $48,05 \pm 25,07$ & \\
\hline 12 month & $70,38 \pm 20,33$ & $70,65 \pm 20,75$ & $69,67 \pm 19,44$ & \\
\hline \multicolumn{5}{|l|}{ V } \\
\hline 1 month & $54,07 \pm 18,72$ & $54,77 \pm 18,61$ & $52,07 \pm 19,13$ & \multirow[t]{3}{*}{$p=0,98$} \\
\hline 6 month & $55,97 \pm 17,51$ & $56,79 \pm 17,11$ & $53,66 \pm 18,60$ & \\
\hline 12 month & $60,10 \pm 16,52$ & $61,00 \pm 15,67$ & $57,72 \pm 18,61$ & \\
\hline
\end{tabular}

Table 3 Physical and mental health data of patients with the ACS after CABG based on education

\begin{tabular}{lllll}
\hline Indicators & $\begin{array}{l}\text { Total } \\
\text { mean } \pm \text { SD }\end{array}$ & $\begin{array}{l}\text { Higher education } \\
\text { mean } \pm \text { SD }\end{array}$ & $\begin{array}{l}\text { Secondary education } \\
\text { mean } \pm S D\end{array}$ & $\begin{array}{l}\text { P(education difference } \\
\text { within the group) }\end{array}$ \\
\hline GH & & & $55,70 \pm 15,26$ & $\mathrm{p}=0,27$ \\
1 month & $56,53 \pm 16,31$ & $57,77 \pm 17,83$ & $64,59 \pm 16,18$ & \\
6 month & $65,49 \pm 16,75$ & $66,85 \pm 17,62$ & $67,48 \pm 17,35$ & \\
12 month & $69,54 \pm 17,72$ & $72,85 \pm 17,97$ & & $\mathrm{p}=0,59$ \\
$\mathrm{PH}$ & & & $56,01 \pm 26,97$ & \\
1 month & $57,25 \pm 27,51$ & $59,10 \pm 28,42$ & $56,76 \pm 25,33$ & \\
6 month & $57,82 \pm 25,25$ & $59,43 \pm 25,25$ & & \\
\hline
\end{tabular}


Table Continued..

\begin{tabular}{|c|c|c|c|c|}
\hline Indicators & $\begin{array}{l}\text { Total } \\
\text { mean } \pm S D\end{array}$ & $\begin{array}{l}\text { Higher education } \\
\text { mean } \pm S D\end{array}$ & $\begin{array}{l}\text { Secondary education } \\
\text { mean } \pm S D\end{array}$ & $\begin{array}{l}\text { P(education difference } \\
\text { within the group) }\end{array}$ \\
\hline 12 month & $62,65 \pm 26,46$ & $65,65 \pm 26,01$ & $60,78 \pm 26,74$ & \\
\hline \multicolumn{5}{|l|}{ RP } \\
\hline 1 month & $55,26 \pm 34,36$ & $56,56 \pm 34,43$ & $54,40 \pm 34,47$ & \multirow[t]{3}{*}{$p=0,94$} \\
\hline 6 month & $53,31 \pm 28,23$ & $53,75 \pm 28,30$ & $53,02 \pm 28,34$ & \\
\hline 12 month & $62,65 \pm 26,46$ & $65,65 \pm 26,01$ & $60,78 \pm 26,74$ & \\
\hline \multicolumn{5}{|l|}{ BP } \\
\hline 1 month & $55,14 \pm 23,67$ & $55,87 \pm 25,65$ & $54,65 \pm 22,37$ & \multirow[t]{3}{*}{$p=0,87$} \\
\hline 6 month & $55,30 \pm 23,94$ & $56,03 \pm 24,90$ & $54,82 \pm 23,42$ & \\
\hline 12 month & $65,26 \pm 26,97$ & $66,94 \pm 26,72$ & $64,21 \pm 27,25$ & \\
\hline \multicolumn{5}{|l|}{$\mathrm{MH}$} \\
\hline 1 month & $57,82 \pm 16,83$ & $56,31 \pm 15,99$ & $58,84 \pm 17,39$ & \multirow[t]{3}{*}{$p=0,80$} \\
\hline 6 month & $67,81 \pm 15,27$ & $67,28 \pm 15,49$ & $68,15 \pm 15,19$ & \\
\hline 12 month & $70,66 \pm 15,76$ & $71,27 \pm 15,78$ & $70,29 \pm 15,83$ & \\
\hline \multicolumn{5}{|l|}{ RE } \\
\hline 1 month & $48,19 \pm 39,35$ & $51,23 \pm 40,16$ & $46,15 \pm 38,89$ & \multirow[t]{3}{*}{$p=0,88$} \\
\hline 6 month & $60,43 \pm 34,56$ & $64,17 \pm 35,46$ & $57,97 \pm 33,92$ & \\
\hline 12 month & $65,00 \pm 26,94$ & $68,23 \pm 27,16$ & $62,99 \pm 26,78$ & \\
\hline \multicolumn{5}{|l|}{ SF } \\
\hline 1 month & $59,76 \pm 22,72$ & $60,67 \pm 22,51$ & $59,15 \pm 22,97$ & \multirow[t]{3}{*}{$p=0,87$} \\
\hline 6 month & $47,58 \pm 22,89$ & $47,25 \pm 22,57$ & $47,80 \pm 23,21$ & \\
\hline 12 month & $70,73 \pm 20,33$ & $70,52 \pm 21,72$ & $70,86 \pm 19,56$ & \\
\hline \multicolumn{5}{|l|}{ V } \\
\hline 1 month & $54,13 \pm 19,00$ & $55,49 \pm 17,48$ & $53,22 \pm 20,00$ & \multirow[t]{3}{*}{$p=0,51$} \\
\hline 6 month & $56,11 \pm 17,75$ & $57,83 \pm 15,24$ & $54,98 \pm 19,22$ & \\
\hline 12 month & $60,46 \pm 16,71$ & $63,08 \pm 14,18$ & $58,83 \pm 18,01$ & \\
\hline
\end{tabular}

Table 4 The difference in the indicators of patients with ACS after CABG for each indicator after I and 6 months, I and I2 months

\begin{tabular}{lllll}
\hline \multicolumn{3}{l}{ Indicators } & \multicolumn{3}{l}{ Under 65 years } & After 65 years \\
& Changes & $\mathbf{P}$ & Changes & $\mathbf{P}$ \\
\hline $\mathrm{GH}$ & & & & \\
1 and 6 month & $+10,13$ & $\mathrm{p}<0,001$ & $+5,56$ & $\mathrm{p}=0,13$ \\
1 and 12 month & $+13,68$ & $\mathrm{p}<0,001$ & $+10,34$ & $\mathrm{p}=0,001$ \\
$\mathrm{PH}$ & & & & \\
1 and 6 month & $+2,28$ & $\mathrm{p}=0,21$ & $-3,21$ & $\mathrm{p}=0,04$ \\
1 and 12 month & $+7,07$ & $\mathrm{p}<0,001$ & $+1,62$ & $\mathrm{p}=0,03$ \\
$\mathrm{RP}$ & & & & \\
1 and 6 month & $-0,41$ & $\mathrm{P}=0,93$ & $-5,77$ & $\mathrm{P}=0,07$ \\
1 and 12 month & $+0,36$ & $\mathrm{p}=0,72$ & $+3,88$ & $\mathrm{p}=0,49$ \\
$\mathrm{BP}$ & & & & \\
1 and 6 month & $+1,46$ & $\mathrm{p}=0,42$ & $-2,63$ & $\mathrm{p}=0,13$ \\
1 and 12 month & $+12,53$ & $\mathrm{p}=0,001$ & $+4,05$ & $\mathrm{p}=0,17$ \\
$\mathrm{MH}$ & & & & \\
1 and 6 month & $+12,52$ & $\mathrm{p}<0,001$ & $+4,87$ & $\mathrm{p}=0,001$ \\
1 and 12 month & $+15,16$ & $\mathrm{p}<0,001$ & $+8,29$ & $\mathrm{p}<0,001$ \\
RE & & & & \\
\hline
\end{tabular}




\begin{tabular}{|c|c|c|c|c|}
\hline \multirow{2}{*}{ Indicators } & \multicolumn{2}{|c|}{ Under 65 years } & \multicolumn{2}{|c|}{ After 65 years } \\
\hline & Changes & $\mathbf{P}$ & Changes & $\mathbf{P}$ \\
\hline 1 and 6 month & $+14,51$ & $p<0,001$ & $+6,73$ & $p=0,02$ \\
\hline 1 and 12 month & $+16,66$ & $\mathrm{p}<0,001$ & $+18,03$ & $p=0,004$ \\
\hline \multicolumn{5}{|l|}{ SF } \\
\hline 1 and 6 month & $-11,37$ & $p<0,001$ & $-14,55$ & $p<0,001$ \\
\hline 1 and 12 month & $-11,33$ & $p<0,001$ & $+8,45$ & $p=0,01$ \\
\hline \multicolumn{5}{|l|}{ V } \\
\hline 1 and 6 month & $+2,8$ & $p=0,008$ & $+0,10$ & $p=0,78$ \\
\hline 1 and 12 month & $+6,76$ & $p=0,001$ & $+4,54$ & $p=0,02$ \\
\hline
\end{tabular}

Vitality (VT) in the dynamics increased after CABG, but insignificantly: from $54,07 \pm 18,72$ points to $60,10 \pm 16,52$ points throughout the year. This attests to the patients' fatigue, decreasing of vitality. Mental Health $(\mathrm{MH})$ in patients after CABG increased from $58,23 \pm 17,07$ points up to $71,04 \pm 15,87$ points and can be characterized as average figure. This reflects the depression, anxiety among respondents. Social Functioning (SF) in patients after CABG raises to $70,38 \pm 20,33$ points and can be interpreted as that patients with ACS after CABG had not any communication restrictions because of their physical or emotional state.

Bodily Pain (BP) after CABG increased insignificantly from $55,09 \pm 23,79$ points to $64,67 \pm 27,06$ points, this demonstrating influence of pain on daily life, including work, housework and other activities in- and outdoors.

Patients assessed their General Health (GH) after CABG in $69,15 \pm 17,63$ points, that is characterized as average.

Aggregated indexes of physical and mental health in patients after 12 month after CABG is $63,26 \pm 24,54$ and $66,93 \pm 19,88$ respectively.

\section{Discussion}

By the results of analysis of quality of life in patients with acute coronary syndrome, who underwent $\mathrm{CABG}$, it was found, that the level of physical functioning (PF), which reflects the degree of physical condition limiting physical activity of the patient, was $57.48 \pm 27.46$ points after 1 month after discharge and $62.56 \pm 26.31$ points after 12 months after discharge. The level of role-playing activity (RP), showing the influence of physical condition on daily activities, was $55.22 \pm 34.21$ points after 1 month after discharge and $56.68 \pm 27.17$ points after 12 months after discharge. The lower the level, the more pronounced the limitation of daily activities. The level of bodily pain (BP), showing to what extent the pain syndrome limits the patient's activity at home and outside, was $55,09 \pm 23,79$ points after 1 month after discharge and $64.67 \pm 27.06$ points after 12 months after discharge. Patients evaluated their own general health (GH) approximately 1 month later after discharge by $56.70 \pm 16.23$ points and $69.15 \pm 17.63$ points after 12 months after discharge. The vitality (VT) of patients with ACS was $54.07 \pm 18.72$ points after 1 month after discharge and $60,10 \pm 16,52$ points in 12 months after discharge. Social functioning (SF), which determines the influence of the physical or emotional state of the patient on social activity, was $59.90 \pm 22.60$ points after 1 month after discharge and 70,38 $\pm 20,33$ through 12 months after discharge.

Role-Emotional function (RE), due to the emotional state, showing the influence of the emotional state on the patient's workability, was
$49.05 \pm 39.08$ points after 1 month after discharge and $66.22 \pm 27.19$ points after 12 months after discharge. The level of the mental health (MH) was $58.23 \pm 17.07$ points after 1 month after discharge and $71.04 \pm 15.87$ after 12 months extracts. After a month after discharge, the physical component of the quality of life of patients with ACS after CABG was $56.12 \pm 25.42$ points, the psychological component $-55.31 \pm 24.36$ points. The physical component of the quality of life of patients with ACS after 12 months of CABG after discharge was $63.26 \pm 24.54$ points, the psychological component was $66.93 \pm 19.88$ points. During the survey period, the mental component of the quality of life in patients, who underwent PCI and CABG due to the ACS was higher than the physical component.

The homogeneous tendency of average indexes BP, GH, VT, SF, $\mathrm{MH}, \mathrm{PF}, \mathrm{RE}, \mathrm{RP}(\mathrm{p}<0.001)$ was established.

The assessment of quality of life in two age groups (up to 65 years and over 65 years), between men and women, as well as in people who had secondary and higher education revealed a statistically insignificant difference in indicators. According to the Maznyczka A.M. and other, ${ }^{4} 75 \%$ (241 patients) of patients, including 235 patients after PCI and 88 patients after CABG, was working before they got technologically advanced medical treatment. 162 patients $(93 \%)$ after PCI and 51 patients $(77 \%)$ after CABG returned to their work. Throughout the year 147 patients (85\%) after PCI and 41 patients (62\%) after CABG was continuing their work. Six weeks after PCI and 13 weeks after $C A B G$ is the average time that was needed to patients to get back to their work $(\mathrm{p}=0,001)$.

Mouin SA et al..$^{5}$ consider that $\mathrm{CABG}$ procedure in patients with diabetes mellitus and multivessel coronary lesion provides better quality of life and health in a period from 6 month to 2 years after initial treatment than implantation of drug-eluting stent. Nevertheless, the effect size is too small and cannot be clinically significant.

Indicators and predictors of readmission after ACS and revascularization throughout the first year after acute myocardial infarction studied in 3283 patients in multi-centered register of ACS.

In the assessment of Kaplan-Mayer, the frequency of readmission due to ACS and revascularization is $6,8 \%$ and $4,1 \%$ accordingly. The most reliable predictors for readmission after ACS are: coronary bypassing before hospitalization due to MI (OP 2,12, 95\% CI from 1,45 to 3,10 ), female (OP $1,67,95 \%$ CI from 1,23 to 2,25 ) and inhospital PCI (OP 1,85, 95\% CI from 1,28 to 2,69). Also the most reliable predictors for following revascularization was established, there are multivessel lesion of coronary arteries OP 2,89, 95\% CI from 1,90 to 4,39) and in-hospital implantation of metal stent (OP $2,08,95 \%$ CI from 1,19 to 3,63$)$. The global register of acute coronary 
inventions established, that the risk of death is not related to risks of readmission in patients with ACS or myocardial revascularization. The above-mentioned multidimensional predictors can help to reveal patients with high risks of ACS development and revascularization. For these patients intensification of second-line therapy for the prevention of MI is justified. ${ }^{6-8}$

\section{Summary}

Thus, it can be concluded that after the surgical myocardial revascularization, the number of patients with an average and increased quality of life has increased. The main reasons that limited the quality of life in patients with ACS who underwent the CABG were the following: the need to limit physical activity and labor activity, as well as the presence of depression, anxiety. This indicates that the rehabilitation of cardiac patients should begin from the very first days of the ACS with the participation of a psychologist and a social worker and should be continued for the following two years.

Implementation of SF-36 questionnaire demonstrated the ability to use this method for control indicators of quality of life and assessment of the measures aimed at improving the quality of life after ACS. Subsequent similar studies with a descriptive sample throughout Kazakhstan will provide a quantitative assessment of the quality of life in patients after the OKS that can be used in the development of State Health programs including issues of improving the level and quality of medical care.

\section{Financing}

The research has no sponsorship.

\section{Acknowledgments}

None.

\section{Conflicts of interest}

The authors declare no conflict of interest.

\section{References}

1. Berkinbayev SF, Dzhunusbekova GA, Musagaliyeva AT, et al. Implementation results of integrated model of medical care for acute myocardial infarction. News of the national academy of sciences of the republic of Kazakhstan series of biological and medical. 2017;2(320):513.

2. Kamaliev MA, Almukhanova AB. Diseases of the circulatory system in the republic of Kazakhstan and the provision of high-tech medical care to the population. Science and education - our future. Ajman; 2015:30-33.

3. Ware JE, Snow KK, Kosinski M, et al. Sf-36 Health Survey. Manual and interpretation guide. Lincoln, RI: quality metric incorporated; 2000.

4. Maznyczka AM, Howard JP, Banning AS, et al. A propensity matched comparison of return to work and quality of life after stenting or coronary artery bypass surgery. Open Heart. 2016:3(1);e000322.

5. Abdallah MS, Wang K, Magnuson EA, et al. Quality of life after pci vs. cabg among patients with diabetes and multivessel cad: results from the freedom trial. JAMA. 2013;310(15):1581-1590.

6. Arnold SV, Smolderen KG, Kennedy KF, et al. Risk factors for rehospitalization for acute coronary syndromes and unplanned revascularization following acute myocardial infarction. J Am. Heart Assoc. 2015:4;e001352.

7. Morgan TO. Cost, quality, and risk: measuring and stopping the hidden costs of coronary artery bypass graft surgery. Am J Health Syst Pharm. 2005:62(18);2-5.

8. Puskas JD, Williams WH, Mahoney EM, et al. Off-pump versus conventional coronary artery bypass grafting: early and 1-year graft patency, cost, and quality-of-life outcomes: A randomized trial. JAMA. 2004:291;1841-1849. 